\title{
Short Communication \\ Prevalence and molecular detection of infectious laryngotracheitis virus in chickens in selected areas of Bangladesh
}

\author{
M.Z. Ali and M. Giasuddin* \\ Animal Health Research Division, Bangladesh Livestock Research Institute, Savar, Dhaka 1341, \\ Bangladesh.
}

\begin{abstract}
Infectious laryngotracheitis (ILT) is a viral disease of poultry species caused by infectious laryngotracheitis virus (ILTV) that shows high morbidity and mortality. The present study was under taken for ILTV prevalence in broiler and layer chickens from four different geographical areas including Bogura, Gazipur, Chattogram and Dhaka districts during 2017 to 2018. Total 350 tracheal swabs were collected and were evaluated by real time RT-PCR (rRT-PCR). The overall 5.14\% (18/350) ILTV prevalence was found that included 6.5\% (13/200) in layer and 3.33\% (5/150) in broiler chickens. The prevalence of ILTV was highest (10\%) in layer chickens under age below 20 weeks and broiler chicks showed ILTV (1. 42\%) infection when they were 7-14 days old. Winter season showed highest $6.6 \%$ prevalence whereas $5 \%$ and $3 \%$ prevalence were noticed at summer and rainy seasons, respectively.
\end{abstract}

Key words: Infectious laryngotracheitis virus, chicken, rRT-PCR, prevalence

Bang. J. Lives. Res. Vol. 27(1\&2), 2020: P.113-117 https://doi.org/10.3329/bjlr.v27i1.55175

\section{Introduction}

Infectious Laryngotracheitis (ILT) is an important respiratory disease of chicken caused by gallid herpes virus-I belonged to family Herpesviridae, subfamily Alphaherpesvirinae, genus Iltovirus. It is an enveloped, nonsegmented and linear double-stranded DNA virus. Clinical signs associated with the acute form of the disease include gasping, depression, nasal discharge, conjunctivitis, and secretion of bloody mucus (OIE, 2008). On postmortem infected chickens shows hemorrhages and mucus plugs in trachea (Ali, 2020; Ali and

\section{Materials and Methods}

A total of 350 tracheal swabs were collected from suspected cases of ILT disease from broiler $(n=150)$ and layer $(n=200)$ chickens of selected farms of Gazipur, Bogura, Chattogram and Dhaka district of Bangladesh. After collection, the samples were kept in viral transport medium (VTM) containing antibiotics and then
Hasan, 2018; Bhuiyan et al., 2019a). The birds do not show any clinical disease also show few pathological signs and lesions that include closed eyes, conjunctivitis, swelling of the infraorbital sinuses, persistent nasal discharges and mild tracheitis. The disease has been reported in Bangladesh in 2010 (Islam et al., 2010; Ali et al., 2015). The aim of the research was to determination of the prevalence of ILTV in selected areas of Bangladesh, and identification of ILTV in the samples collected from the areas. transported to the Virology Laboratory, Animal Health Research Division, BLRI, Savar, Dhaka and stored at $-80^{\circ} \mathrm{C}$ until tested. The swab samples were grinded and homogenized, and $10 \%$ suspension was prepared by using phosphate buffer solution (PBS). The suspension was centrifuged at $4500 \mathrm{rpm}$ for $10 \mathrm{~min}$ for the 
collection of supernatant and genomic DNA was extracted by QIAamp DNA Mini Kit, according to the manufacturer's guidelines. Then rRT-PCR was performed for the confirmation of ILTV positive samples by reference primer and probe (Table 1).

\section{Results and Discussion}

The overall prevalence of ILTV in the chickens tested were $5.14 \%(18 / 350)$ of which the prevalence was $3.33 \%$ in broiler and $6.50 \%$ in layer chickens. Bogura showed the highest $(7.00 \%)$ detection whereas Dhaka was the lowest (2.00\%) (Figure 1). Islam et al., (2010) demonstrated the comparative highest infection of ILTV in Gazipur district. Bogura has the

highest density of Sonali chickens (cross-bred) in Bangladesh that may influence the rapid transmission of infectious pathogens (Islam et al., 2010; Ali, 2018). Population density increases the chance of ILTV transmission in India (Gowthaman et al., 2014) and Thailand (Couto et al., 2015).

Table 1. Primer and probe sequence used for the detection of infectious laryngotrachitis virus.

\begin{tabular}{|c|c|c|c|}
\hline $\begin{array}{l}\text { Primer anc } \\
\text { prove }\end{array}$ & Primer sequence (5' to 3 ') & $\begin{array}{l}\text { Target } \\
\text { gene }\end{array}$ & Reference \\
\hline gB-S & CAGTATCTGGCATCGCCTCAT & \multirow[t]{3}{*}{ gB gene } & \multirow{3}{*}{$\begin{array}{l}\text { Zhao et al } \\
(2013)\end{array}$} \\
\hline $\mathrm{gB}-\mathrm{A}$ & CCTGGGAACAGAACCTGAACT & & \\
\hline Probe & FAM-CTAACCCGTTCG CCGCACTCG-BHQ & & \\
\hline
\end{tabular}

Additionally, the prevalence was highest $6.5 \%$ in layer chickens which was highest during 20 weeks of age as $10 \%(6 / 60)$, then $3.75 \%$ at 21 40 weeks of age and $6.67 \%(4 / 60)$ at above 41 weeks of age. On the other hand, in broiler chickens showed highest $5 \%$ prevalence at midage (between 15-32 days), (Table 2). Highest incidence of ILTV was recorded as $25.00 \%$ in layer chickens in Kazi farm and the lowest incidence was recorded as $14.28 \%$ in layer chickens of Paragon poultry farm in
Bangladesh, and they showed $100 \%$ mortality of chickens described by Islam et al. (2010). The samilar observation was also made by Andrease et al. (1989), Beltrán et al. (2017), Nadimpalli et al. (2017) and Mijanur et al. (2018) in several investigations. The detection was highest in winter than in any other seasons (Figure 2). Similar highest prevalence in winter season was recorded by several researchers (Lowen et al., 2008; Gilchrist, 2005; Ali et al., 2019; Bhuiyan et al., 2019b).

Table 2. Prevalence of infectious laryngotrachitis virus of chickens at different ages

\begin{tabular}{ccccccc}
\hline Type & Age & $\begin{array}{c}\text { Number } \\
\text { Sample }\end{array}$ & Positive & $\begin{array}{c}\text { No. of positive } \\
\text { sample }(\%)\end{array}$ & 95\% CI & $\begin{array}{c}\mathrm{p} \\
\text { value }\end{array}$ \\
\hline Broiler & 7-14 Day & 70 & 1 & $1(1.43)$ & $0.04-7.0$ & 0.02 \\
& 15-32 Day & 80 & 4 & $4(5.00)$ & $1.38-12.31$ & \\
Layer & Total & 150 & 5 & $5(3.33)$ & $1.09-7.61$ & \\
& 21-40 week & 60 & 6 & $6(10.00)$ & $3.76-20.51$ & 0.332 \\
& $\geq 41$ week & 80 & 3 & $3(3.75)$ & $0.78-10.57$ & \\
& Total & 60 & 4 & $4(6.67)$ & $1.85-16.20$ & \\
\hline
\end{tabular}




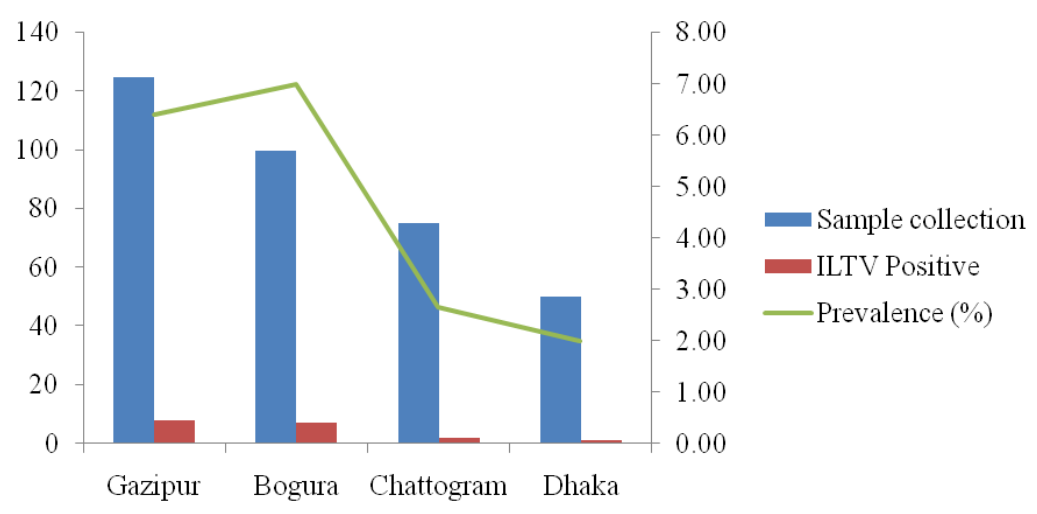

Figure 1: Prevalence of infectious laryngotracheitis disease at different areas of Bangladesh.

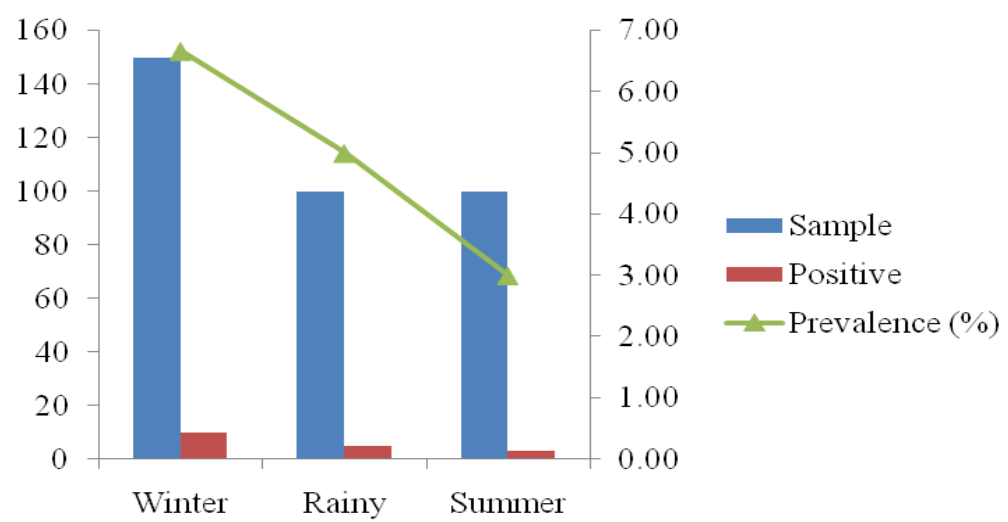

Figure 2: Prevalence of infectious laryngotracheitis disease at different seasons.

\section{Conclusion}

In the study, the overall prevalence estimates of ILTV in broiler and layer chicken were demonstrated. Altogether, this study indicates

\section{Acknowledgments}

We acknowledge the cordial support of all laboratory staff, poultry farm owners, and flock workers to complete the research. The that ILTV is circulating in both commercial layer and broiler chicken and its prevalence is higher in winter season.

research was funded by the BLRI Research Fund. 


\section{References}

Ali, M.Z. 2020. Combined usage of rHVT-H5 and Re-6 vaccines towards an effective avian influenza vaccination program for commercial layer chickens. Stamford J. Microbiol. 10(1):9-11.

Ali, M.Z. 2020. Common Respiratory Diseases of Poultry in Bangladesh: A Review. SAARC J. Agri. 18(1):1-11.

Ali, M.Z. and Hsan, B. 2018. Follow Up of Maternally Derived Antibodies Titer against Economically Important Viral Diseases of Chicken. Poultry Sci. J. 6(2):149-154.

Ali, M.Z. and Islam, M.M. 2021. Characterization of $\beta$-lactamase and quinolone resistant Clostridium perfringens recovered from broiler chickens with necrotic enteritis in Bangladesh. Iranian J. Vet. Res. 22(1):48-54.

Ali, M.Z., Islam, M.M. and Zaman, S. 2020. Effects of Turmeric Powder on Clostridium Perfringens Load in Broiler Chickens. SAARC J. Agric. 18(1):209-218.

Ali, M.Z., Park, J.E. and Shin, H.J. 2019. Serological survey of avian Metapneumovirus infection in chickens in Bangladesh. J. Appl. Poultry Res. 28(4):1330-1334.

Ali, M.Z., Rahman, M.M. and Sultana, S. 2015. Seroprevalence of Mycoplasma gallisepticum antibody by ELISA and serum plate agglutination test of laying chicken. Vet. World 8(1):9-14.

Ali, MZ. 2018. The seroprevalence study of Reticuloendotheliosis virus infection in chicken in Bangladesh. Egypt. J. Vet. Sci. 49(2):179-186.

Ali, M.Z., Islam, E. and Giasuddin, M. 2019. Outbreak investigation, molecular detection, and characterization of foot and mouth disease virus in the Southern part of Bangladesh. J. Adv. Vet. Anim. Res. 6(3):346-354.

Andreasen, J.R., Brown, J., Glisson, J.R. Villegas, P. 1988. A microtitration and neutralization test for infectious laryngotracheitis virus. Tijdschr Diergeneeskd 113(2):61-5.

Beltrán, G., Williams, S. M., Zavala, G., Guy, J. S. and García, M. 2017. The route of inoculation dictates the replication patterns of the infectious laryngotracheitis virus (ILTV) pathogenic strain and chicken embryo origin (CEO) vaccine. Avian Pathol. 46(6):585-593.

Bhuiyan, Z.A., Ali, M.Z., Moula, M.M., Bary, M.A., Arefin, N., Giasuddin, M. and Khan, Z.U.M., 2019a. Seroprevalence of major avian respiratory diseases in broiler and sonali chicken in selected areas of Bangladesh. J. Adv. Vet. Anim. Res. 6(4):561-566.

Bhuiyan, Z.A., Ali, M.Z., Moula, M.M., Giasuddin, M. and Khan, Z.U.M. 2019b. Prevalence and molecular characterization of infectious bronchitis virus isolated from chicken in Bangladesh, Vet. World 12(6):909-915.

Couto, R. M., Braga, J. F. V., Gomes, S. Y., Resende, M., Martins, N. R. and Ecco, R. 2015. Natural concurrent infections associated with infectious laryngotracheitis in layer chickens. J. Appl. Poultry Res. 25(1):113-128.

Gilchrist, P. 2005. Involvement of free-flying wild birds in the spread of the viruses of avian influenza, Newcastle disease and infectious bursal disease from poultry products to commercial poultry. World's Poultry Sci. J. 61(2):198-214.

Gowthaman, V., Singh, S.D., Dhama, K., Barathidasan, R., Mathapati, B.S., Srinivasan, P. and Ramakrishnan, M.A. 2014. Molecular detection and characterization of infectious laryngotracheitis virus (Gallid herpesvirus1) from clinical samples of commercial poultry flocks in India. VirusDis. 25(3):345-349.

Islam, M.S., Khan, M.S.R., Islam, M.A. and Hassan, J. 2010. Isolation and characterization of infectious laryngotracheitis virus in layer chickens. Bang. J. Vet. Med. 8(2):123-130.

Lowen, A.C., Steel, J., Mubareka, S. and Palese, P. 2008. High temperature (30 C) blocks aerosol but not contact transmission of influenza virus. J. Virol. 82(11):56505652.

May, H.G. and Tittsler, R.P. 1925. Tracheolaryngitis in poultry. J. Am. Vet. Med. Assoc. 67: 229-231. 
Nadimpalli, M., Lee, S.W., Devlin, J.M., Gilkerson, J.R. and Hartley, C.A. 2017. Impairment of infectious laryngotracheitis virus replication by deletion of the UL [-1] gene. Arch. Virol. 162(6):1541-1548.

OIE. 2008. Manual of Diagnostic Tests and Vaccines for Terrestrial Animals. OIE World Organization for Animal Health. Paris. Available from: http://www.oie.int/eng/normes/mmanual/A _00104.html.

Rahman, M.M., Uddin, M.K., Hassan, M.Z., Rahman, M.M., Ali, M.Z., Rahman, M.L., Akter, M.R. and Rahman, M.M., 2018. Seroprevalence study of infectious laryngotracheitis virus antibody of commercial layer in Gazipur Districts of Bangladesh. Asian J. Med. Biological Res. 4(1):1-6.

Zhao, Y., Kong, C., Cui, X., Cui, H., Shi, X., Zhang, X. and Wang, Y. 2013. Detection of infectious laryngotracheitis virus by realtime PCR in naturally and experimentally infected chickens. PloS one 8(6):e67598. 